\title{
Effect of typical and atypical antipsychotic drugs on serum C- reactive protein and lipid profile in schizophrenic patients
}

\author{
Faris A Ahmed \\ Department of Physiology, Ninevah College of Medicine, University of Mosul, Iraq

$\frac{\text { Received }}{4.5 .2012} \quad \frac{\text { Accepted }}{21.9 .2012}$

\begin{abstract}
Objectives: To assess the effect of quetiapine and fluphenazine on serum high sensitivity C-reactive protein (hs-CRP) and serum lipid profile in schizophrenic patients.
\end{abstract}

Patients and methods: The subjects comprised two groups of twenty seven newly diagnosed schizophrenic patients for each group. The first group was treated orally with quetiapine at a dose 200-500 mg/day. The second group was treated with fluphenazine intramuscularly at a dose $25 \mathrm{mg}$ every 4 weeks. Twenty seven healthy volunteers were also included as a control group. The patient and the control groups were age and sex matched. The patients were diagnosed by a psychiatrist on the basis of semi-structured interview to determine DMS-IV diagnosis. Clinical symptoms were assessed in 14 of the 18 Brief individual Psychiatry Rating Scale (BPRS) items in order to measure the severity of schizophrenia. Fasting blood samples from the patients were taken for analysis before the beginning of quetiapine or fluphenazine treatment and after 8 weeks of the study. Other blood samples were taken from healthy subjects as a control group.

Results: Serum hs-CRP was significantly $(p<0.01)$ higher in the schizophrenic patients before treated by quetiapine or fluphenazine (difference $=382.9 \%$ and $395.1 \%$ of control, respectively) than controls. The measurement of hs-CRP decreased significantly $(p<0.01)$ after quetiapine treatment by $19.1 \%$, while it was increased significantly $(p<0.01)$ after fluphenazine by $12.3 \%$ compared with before treatment values. In the schizophrenic patients, serum total cholesterol (TC) and triglycerides (TG) were significantly higher $(p<0.01)$ than controls, while high density lipoprotein cholesterol (HDL-C) was lower than controls. Quetiapine caused significant increase $(p<0.01)$ in serum TC and TG, while serum HDL-C decreased significantly $(p<0.01)$ compared with the results before treatment. Fluphenazine did not cause any significant change in the lipid parameters. Quetiapine treatment significantly increased $(\mathrm{p}<0.05)$ body mass index $(\mathrm{BMI})$, whereas fluphenazine did not change BMI compared with before treatment values. Base time and after 8 weeks of quetiapine or fluphenazine treatment showed significant decrease in the score of BPRS by quetiapine and fluphenazine.

Conclusion: Quetiapine depressed CRP and caused dyslipidemia. Fluphenazine raised CRP but it had no effect on lipid profile.

Keywords: Schizophrenia, C-reactive protein, quetiapine, fluphenazine 
الخلاصة

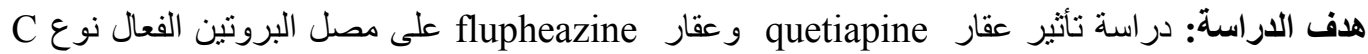

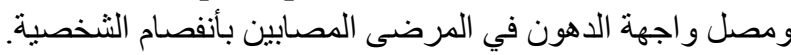
المرضى وطرق العمل: شملت الدر اسة مجمو عتين من المرضى النهى المصابين بأنفصام الثخصية المشخصين حديثا

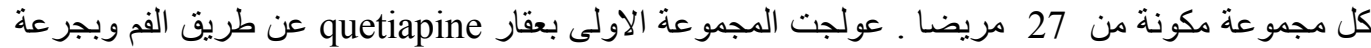

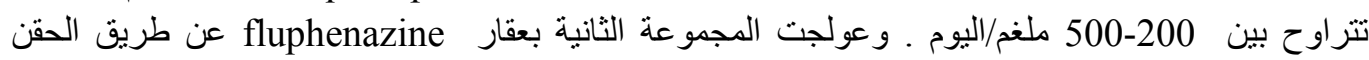

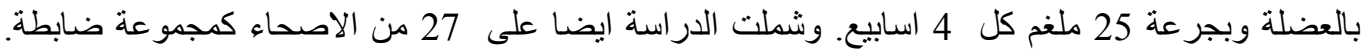

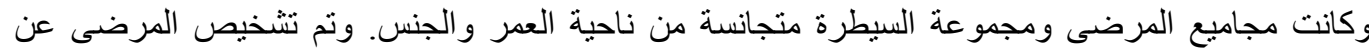

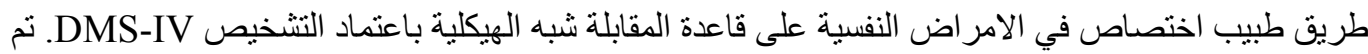

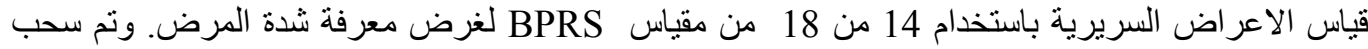
عينات دم من المرضى لاجر اء التحليل قبل علاج

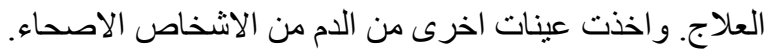

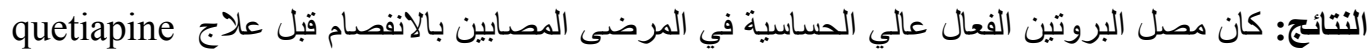
او fluphenazine اعلى معنويا (0.01 > p p) من مجموعة السيطرة (الفرق= 382 \% و و 395 \% م من

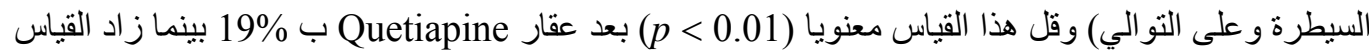

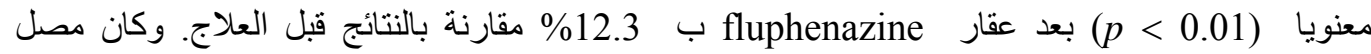

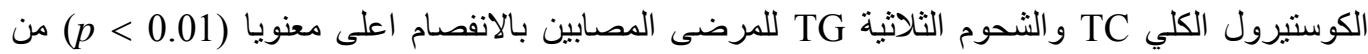

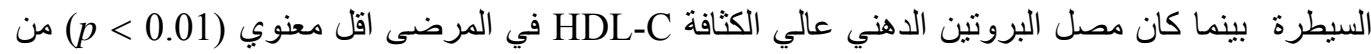

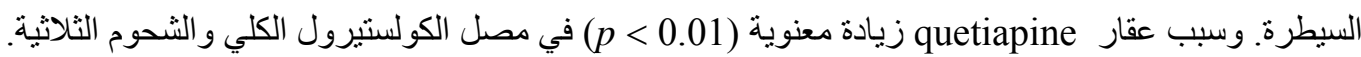

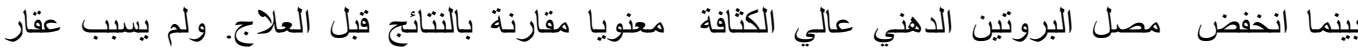

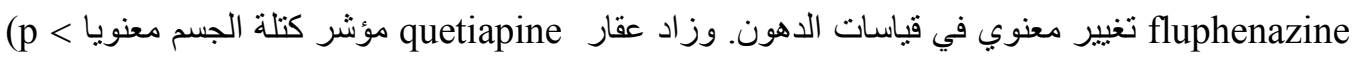

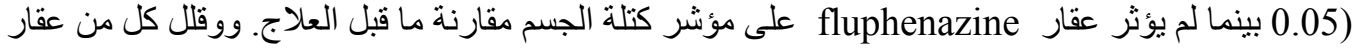

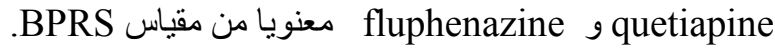
الاستتاج: ثبط عقار quetiapine مصل البروتين الفعال وسبب في تغيير واجهة الدهون. ان عقار

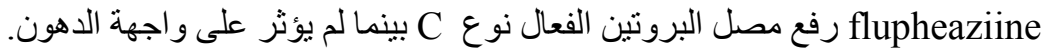

$G_{\text {the positive acute phase reactant }}$ protein. It is synthesized in the liver and has many pathophysiological role in the inflammatory process ${ }^{1}$.

There have been some reports on the use of the elevated CRP level as evidence for an inflammatory etiology for schizophrenia and as indicator for more severe clinical symptoms and psychopathology in schizophrenia ${ }^{2}$. In antipsychotic free patients with schizophrenia, serum high sensitivity CRP (hs-CRP) level was higher than healthy controls and was positively correlated with the severity of the psychopathology ${ }^{3}$. However, elevated serum CRP in schizophrenic patients was associated with the severity of cognitive impairment but not of psychiatric symptoms ${ }^{4,5}$.

Second generation antipsychotics (SGA) are now commonly used because they have lower incidence of extrapyramidal side effects than for first generation antipsychotics (FGA) ${ }^{6}$. Quetiapine is an atypical antipsychotic drugs, used in the treatment of schizophrenia and bipolar disorder ${ }^{7,8}$. Fluphenazine is a conventional typical antipsychotic drug used in the treatment of schizophrenia, it was considered to be used in poor compliance patients, though there is 
little advantage of the drug over oral medication in term of compliance ${ }^{9}$.

Treatment of schizophrenia with different antipsychotic drugs had different results on serum CRP. The atypical antipsychotic drugs, olanzapine or risperidone, decreased serum hs-CRP, while the typical antipsychotic drug, haloperidol, increased serum hs-CRP ${ }^{10}$.

Western studies mainly focus on the effect of different SGA on metabolic outcome but little is known of FGA, still commonly used in Asia ${ }^{11}$. Atypical antipsychotic drugs were associated with metabolic risk more than FGA $^{12}$. Quetiapine was associated with weight gain, hypercholesterolemia and lower high density lipoprotein cholesterol (HDL-C) ${ }^{13}$. In addition, the rate of obesity and metabolic disorder in atypical antipsychotic drugs including quetiapine were high ${ }^{14}$.

Since fluphenazine is still used in the developing countries and little attention was paid on the metabolic side effects of this drug. We suggested this study to compare the effect of this drug as one of FGA with quetiapine as a drug of SGA on serum hs-CRP and lipid profile as risk factors for cardiovascular diseases in schizophrenic patients.

\section{Patients and methods}

This study was a follow up study, conducted in the Outpatient Department of Ibn Sina Hospital, Mosul, Iraq, during the period from September 2010 to April 2011. The laboratory analyses were performed at the Pharmacology laboratory, Ninevah Collage of Medicine, University of Mosul, Iraq. The study was approved by the ethical committee of Ninevah Directorate of Health and the patients were informed by the study. Drugs were given to the patients by a psychiatrist according to their needs. Quetiapine was given as first line treatment, while fluphenazine was given for non-compliance patients in order to achieve the therapeutic dose.

The subjects comprised two groups of newly diagnosed of twenty seven schizophrenic patients for each group. The first group was treated orally with quetiapine at a dose $200-500 \mathrm{mg} /$ day (age range: $15-57$ years, mean $\pm \mathrm{SD}$ : $29.9 \pm 9.7$ years). The second group was treated with fluphenazine intramuscularly at a dose $25 \mathrm{mg}$ every 4 weeks (age range 19-55 years, mean \pm SD: $30.1 \pm 7.2$ years). The treated patients were reevaluated after 8 weeks. Twenty seven healthy volunteers (age range: 18-40 years, mean \pm SD: $28.8 \pm 4.1$ years) were also included as a control group. The patient and the control groups were age and sex matched. The patients were diagnosed by a psychiatrist on the basis of semi-structured interview to determine DMS-IV diagnosis. Clinical symptoms were assessed in 14 of the 18 Brief Individual Psychiatry Rating

Scale (BPRS) items in order to measure the severity of schizophrenia.

All patients and controls were neither alcoholics nor smokers and they were not hospitalized. Patients and controls taking other medications during the study period were excluded. 
Fasting blood samples $(5 \mathrm{~mL})$ from the patients were taken before the beginning of quetiapine or fluphenazine treatment and after 8 weeks of the study. Other blood samples were taken from healthy subjects as a control group. Serum was obtained from the blood samples and analyzed by using colorimetric method for hs-CRP ${ }^{15}$. Serum total cholesterol (TC), HDL-C, and triglycerides (TG) were determined by using enzymatic methods ${ }^{16}$.

Data are presented as mean $\pm \mathrm{SD}$. Unpaired Student $\mathrm{s}$ t-test was used to compare between patient and control parameters. Paired t-test was used to compare the follow up parameters within the patient group. Chie square test was used in order to find the significance of the drug response. $\mathrm{P}$ values less than 0.05 were considered significant. Statistical analysis was performed using SPSS package version 17.

\section{Results}

Table 1 shows that serum hs-CRP was significantly $(\mathrm{p}<0.01)$ higher in the schizophrenic patients before quetiapine and fluphenazine treatment (difference $=382.9 \%$ and 395.1 of control, respectively) than controls. This measurement of hs-CRP decreased significantly after quetiapine treatment by $19.1 \%$, while it was increased significantly after fluphenazine by $12.3 \%$ compared with before treatment values.

Table 1. Serum hs-CRP, TC, HDL-C, and TG in schizophrenic patients treated with quetiapine or fluphenazine

\begin{tabular}{|c|c|c|c|c|}
\hline Study groups & $\begin{array}{c}\text { hs-CRP } \\
(\mu \mathrm{g} / \mathrm{L})\end{array}$ & $\begin{array}{c}\mathrm{TC} \\
\mathrm{mmol} / \mathrm{L}\end{array}$ & $\begin{array}{c}\text { HDL-C } \\
\mathrm{mmol} / \mathrm{L}\end{array}$ & $\begin{array}{c}\mathrm{TG} \\
\mathrm{mmol} / \mathrm{L}\end{array}$ \\
\hline Control subjects & $0.41 \pm 0.1$ & $4.3 \pm 0.71$ & $1.22 \pm 0.26$ & $1.55 \pm 0.52$ \\
\hline $\begin{array}{c}\text { Patients } \\
\text { Before quetiapine } \\
\text { treatment } \\
\begin{array}{c}\text { After quetiapine } \\
\text { treatment }\end{array}\end{array}$ & $1.57 \pm 0.3^{\mathrm{a}}$ & $4.7 \pm 0.82^{\mathrm{a}}$ & $1.15 \pm 0.28^{\mathrm{a}}$ & $1.71 \pm 0.61^{\mathrm{a}}$ \\
\cline { 2 - 5 } & $1.27 \pm 0.25^{\mathrm{b}}$ & $5.2 \pm 0.75^{\mathrm{b}}$ & $1.23 \pm 0.30^{\mathrm{b}}$ & $1.88 \pm 0.70^{\mathrm{b}}$ \\
\hline $\begin{array}{c}\text { Patients } \\
\begin{array}{c}\text { Before fluphenazine } \\
\text { treatment }\end{array}\end{array}$ & $1.62 \pm 0.32^{\mathrm{a}}$ & $4.8 \pm 0.72^{\mathrm{a}}$ & $1.12 \pm 0.29^{\mathrm{a}}$ & $1.69 \pm 0.69^{\mathrm{a}}$ \\
\cline { 2 - 5 } $\begin{array}{c}\text { After fluphenazine } \\
\text { treatment }\end{array}$ & $1.92 \pm 0.33^{\mathrm{b}}$ & $4.5 \pm 0.69$ & $1.14 \pm 0.27$ & $1.70 \pm 0.71$ \\
\hline \multicolumn{2}{|c|}{} & & & \\
\hline
\end{tabular}

hs-CRP: high sensitivity c-reactive protein, TC: total cholesterol, HDL-C: high density lipoprotein cholesterol, TG: triglycerides

${ }^{\mathrm{a}} p<0.01$ vs control; ${ }^{\mathrm{b}} p<0.01$ vs pretreatment 
In the present schizophrenic patients before quetiapine or fluphenazine treatment $\mathrm{TC}$ and $\mathrm{TG}$ were significantly $(\boldsymbol{p}<0.01)$ lower, whereas HDL-C was significantly $(\boldsymbol{p}<$ 0.01) lower than controls. Quetiapine caused significant increase $(p<0.01)$ in serum TC and TG (difference: $11.1 \%$ and $10.99 \%$, respectively), while serum HDL-C was decreased significantly $(p<0.01)$ compared with the results before treatment. Fluphenazine did not cause significant change in the lipid parameters.

Quetiapine treatment significantly increased $(p<0.05)$ body mass index (BMI) by $2.9 \%$ compared with pretreatment values $\left(22.64 \pm 2.46 \mathrm{Kg} / \mathrm{m}^{2}\right.$ vs $23.31 \pm 2.55 \mathrm{Kg} / \mathrm{m}^{2}$, respectively), whereas fluphenazine did not change BMI compared with before treatment value $\left(23.21 \pm 2.32 \mathrm{Kg} / \mathrm{m}^{2}\right.$ vs $23.11 \pm$ $2.42 \mathrm{Kg} / \mathrm{m}^{2}$, respectively).

Base time and after 8 weeks of both quetiapine or fluphenazine treatment showed significant decrease in the score of BPRS ( $86 \pm 4.9$ vs 44.8 \pm 4.3 for quetiapine; $81 \pm 4.1$ vs $40.1 \pm$ 4.9 for fluphenazine) $(\mathrm{p}<0.01)$.

\section{Discussion}

The main findings of this study were fluphenazine (FGA) raised hs-CRP while quetiapine (SGA) decreased it. Dyslipidemia and elevated BMI were found by quetiapine but not fluphenazine.

In the present schizophrenic patients before quetiapine or fluphenazine treatment, serum CRP was significantly higher than controls. These results are consistent with other workers $^{5,17}$. There is emerging evidence of increased inflammation in severe mental disorder ${ }^{18}$. Many studies showed that CRP is a reliable marker of cardiovascular disease (CVD) and has thus been incorporated into CVD risk prediction protocols ${ }^{19,20}$. Hepatic CRP production is under the influence of cytokine especially interlukine ${ }^{21}$. Some of these cytokines also rise in parallel with CRP and could be related to symptomatology of schizophrenia ${ }^{22}$.

Quetiapine decreased serum hsCRP significantly in the studied, while fluphenazine increased hs-CRP significantly after 8 weeks of treatment. Haloperidol as a conventional antipsychotic drug raised CRP, while olanzapine an atypical antipsychotic drug depressed $\mathrm{CRP}^{10}$. Moreover, resperidone normalized proinflammatory CRP in n-3 fatty acid deficient rats $^{23}$. The main point in this study was both quetiapine and fluphenazine decreased BPRS significantly; however, quetiapine depressed hs-CRP, while fluphenazine raised it. Therefore, the mechanism of action of quetiapine and fluphenazine on hs-CRP may be different. Further studies are needed in order to evaluate the cause of elevated CRP by typical antipsychotic drugs.

In the schizophrenic patients before quetiapine or fluphenazine treatment, serum $\mathrm{TC}$ and $\mathrm{TG}$ were increased, whereas HDL-C was decreased. These results are consistent with other workers ${ }^{24,25}$. The prevalence of metabolic syndrome is high in schizophrenic and bipolar disorder compared to general population $^{26}$.

Quetiapine increased serum TC and TG in this study, while 
fluphenazine did not change serum TC and TG. There is controversial results for the effect of atypical and conventional antipsychotic drugs on lipid, since atypical but not conventional showed increasing in serum lipids ${ }^{25}$. Individual drugs of typical and conventional antipsychotic drugs had different effect on lipids in the treated patients ${ }^{27}$. Quetiapine was associated with high risk of hyperlipidemia, the possible underlying causes of lipid dysregulation include weight gain, dietary changes, and glucose intolerance $^{28}$. However, Henderson et al. $^{29}$ found that aripirazole treatment for 4 weeks did not change serum TC, HDL-C, and VLDL-C in the schizophrenic patients. The metabolic disturbances by antipsychotic drugs such as dyslipidemia, hypertension and overweight are regarded as added risk factors of CVD for the schizophrenic patients.

In conclusion, quetiapine depressed the proinflammatory factor CRP, associated with metabolic risk by causing dyslipidemia. Fluphenazin had minimal effect on lipid but raised CRP. Further studies are needed to investigate the mechanism of raised CRP by typical antipsychotic drugs.

\section{Acknowledgement}

This work was supported by Ninevah College of Medicine. University of Mosul, Iraq.

\section{References}

1. Roberts WL, Sedrick R, Moulton $\mathrm{L}$, et al. Evaluation of four high sensitivity C-reactive protein methods: Implication for clinical and epidemiological application. Clin Chem 2000;46:416-68.

2. Fan X, Pristach C, Liu EY, et al. Elevated serum levels of C-reactive protein are associated with more severe psychopathology in a subgroup of patients with schizophrenia. Psychiatry Res 2007;149:267-71.

3. Fawzi MH, Fawzi MM. Fawzi MM, Said NS. C-reactive protein serum level in drug free male Egyptian patients with schizophrenia. Psychiatry Res 2011;190:91-7.

4. Dickerson E, Stallings C, Origoni $\mathrm{A}$, et al. C-reactive protein is associated with the severity of cognitive impairment but not of psychiatric symptoms in individuals with schizophrenia, Schizophr Res 2007;93:261-5.

5. Solanki RK, Singh P, Singh M, et al. C-reactive protein (CRP) in patients with schizophrenia: Are they related with symptomatology? JMHHB 2009;15:6-10.

6. Pierri JM. Extrapyramidal symptoms with atypical antipsychotics: incidence, prevention and management. Drug Safety 2005;28:191-208.

7. Cheer SM, Wagstaff AJ. Quetiapine. A review of its use in the management of schizophrenia. CNS Dugs 2004;18:173-199.

8. Mclntyre RS, Soczynska JK, Woldeyohannes $\mathrm{HO}$, et al. A preclinical and clinical rationale for quetiapine in mood syndromes. Expert Opin Pharmacother 2007;8:1211-9. 
9. David A, Adams CE, Eisenbruch $M$, et al. Depot fluphenazine decanoate and enanthate for schizophrenia. Cochrane Database Syst Rev 2005 ; 1:CD000307

10. Diaz FJ, Perez-Iglesias R, Mata I, et al. Possible effects of some antipsychotic drugs on C-reactive protein in a drug-niave psychotic sample. Schizophr Res 2010;121:207-12.

11. Chong MY, Tan $\mathrm{CH}$, Fujii S, et al. Antipsychotic drug prescription for schizophrenia in east Asia: rationale for change. Psychiatry Clin Neurosci 2004;58:61-7.

12. Lee E, Chow LY, Leung CM. Metabolic profile of first and second generation antipsychotics among Chinese patients. Psychiatry Res 2011;185(3):456-8.

13. Choong E, Bondolfi G, Etter M, etal. Psychotropic drug-induced weight gain and other metabolic complications in a Swiss psychiatric population. J Psychiatry Res. 2012 ;46(4):540-8.

14. Tarricone I, Casoria M, Gozzi BF, et al. Metabolic risk factor profile associated with use of second generation antipsychotics: a cross sectional study in a community mental health centre. BMC Psychiatry 2006;6:11.

15. Cummings PJ. Immunoassay. In: Christenson RH, Gregory LC, Johnson LJ, editors. Appleton and Lange's outline review: Clinical Chemistry. McGraw-Hill Company, USA 2001 p:310-315.

16. Stein EA, Myers GL. Lipids, Apolipoproteins and Lipoproteins. In: Burtis CA, Ashood ER. Teitz Fundamentals of Clinical
Chemistry. $4^{\text {th }}$ Ed. Phi ${ }^{\text {th }}$ Ed. Philadelphia: Sauders, 1996:375401.

17. Akanji AO, Ohaeri JU, AlShammri S, Fatania HR, Association of blood levels of Creactive protein with clinical phenotypes in Arab schizophrenic patients. Psychiatry Res 2009;169:56-61.

18. Goldstein BI, Kemp DE, Soczynska JK, Mcintyre RS. Inflammation and the phenomenology, pathophysiology, comorbidity, and treatment of bipolar disorder: a systemic review of the literature. J Clin Psychiatry 2009;70:1078-90.

19. Ridker PM. C-reactive protein: eighty years from discovery to emergence as a major risk marker for cardiovascular disease. Clin Chem 2009;55:209-15.

20. Corrado E, Rizzo M, Coppola G, et al. An update on the role of markers of inflammation in atherosclerosis. J Atheroscler Thromb 2010;17:1-11.

21. Castell JV, Comez-Lechon MJ, David M, et al. Acute-phase response of human hepatocytes: regulation of acute-phase protein synthesis by interleukin-6. Hepatology 1990;12:1179-86.

22. Zhang XY, Zhou DF, Zhank PY, et al. Elevated interleukin-2, interleukin-6 and inteleukin-8 serum levels in neuroleptic-free schizophrenia: associated with psychopathology. Schizoph Res 2002;57:247-58

23. MacNamara RK, Jandacek R, Rider T, Tso P. Chronic 
resperidone normalizes elevated pro-inflammatory cytokine and Creactive protein production in omega-3 fatty acid deficient rats. Eur J Pharmacol 2011;652:152-6.

24. Saari K, Jokainen J, Veijola J, et al. Serum lipids in schizophrenia and other functional psychoses: a general population northern Finalnd 1966 birth cohort survey. Acta Psychiatr Scand 2004;110:279-85.

25. Haung TL, Chen JF. Serum lipid profiles and schizophrenia: effects of conventional or atypical antipsychotic drugs in Taiwan. Schizophr Res 2005;80:55-9.

26. Van whinkle R, De Hert M, van Eyck D, et al. Screening of diabetes and other metabolic abnormalities in patients with schizophrenia and scizoaffective disorder: evaluation of incidence and screening methods. J Clin Psychiatry 2006;67:1493-1500.

27. Meyer JM, Koro CE. The effects of antipsychotic therapy on serum lipids: a comprehensive review. Schizophr Res 2004;70:1-17.

28. Koro CF, Meyer JM. Atypical antipsychotic therapy and hyperlipidemia: a review. Essent Psychchopharmacol 2005;6:148157.

29. Henderson DC, Fan X, Copeland PM, et al. Aripiprazole added to overweight and obese olanzapinetreated schizophrenia patients. J Clin Psychopharmacol 2009;29: 165-9. 